\title{
A Spiral Antenna Sandwiched by Dielectric Layers
}

\author{
Hisamatsu Nakano, Fellow, IEEE, Masakazu Ikeda, Kazuo Hitosugi, and Junji Yamauchi, Member, IEEE
}

\begin{abstract}
An infinitesimally thin spiral antenna, sandwiched by bottom and top dielectric layers having the same relative permittivity, is analyzed under the condition that the dielectric layers are of finite extent and the antenna is backed by an infinite conducting plane. As the thickness of the top dielectric layer increases, the input impedance and axial ratio (AR) vary in an oscillatory fashion, with a period slightly larger than one-half of the guided wavelength of a wave propagating in an unbounded dielectric material. These oscillatory variations are reduced by adding a layer, called the "anti-reflection layer (ARL)," to the top dielectric layer. A representative spiral antenna with an ARL shows a frequency bandwidth of approximately $11 \%$ for a 3-dB AR criterion, having a gain of approximately $13 \mathrm{dBi}(6 \mathrm{dBi}$ higher than a printed spiral antenna without the top dielectric and $A R L$ ) and a voltage standing wave ratio of less than 1.2.
\end{abstract}

Index Terms-Printed spiral antenna, anti-reflection layer (ARL), finite-difference time-domain (FDTD) analysis.

\section{INTRODUCTION}

A SPIRAL antenna located in free space bi-directionally radiates a circularly polarized wave [1]. This bi-directional beam can be changed to a unidirectional beam by backing the spiral with a conducting plane [2], [3]. The space between the spiral and the conducting plane is often filled with a dielectric layer. Such a spiral antenna has been analyzed under the assumption that both dielectric layer and conducting plane are of infinite extent [4], [5].

From the viewpoint of size reduction, a spiral antenna printed on a dielectric layer of finite extent has also been analyzed [6]. The effects of the finite dielectric on the radiation characteristics are discussed, comparing them with those of an infinite dielectric layer.

If a dielectric layer is newly added on top of the spiral and has positive effects on the radiation characteristics (such as the axial ratio (AR) and gain), application areas of the spiral broaden. However, such a spiral antenna with a top dielectric layer has not been analyzed and the radiation characteristics have not been revealed. This paper, therefore, focuses on a spiral antenna with a top dielectric layer, as shown in Fig. 1.

The top dielectric layer in this paper has the same permittivity as the bottom layer (substrate). In other words, the spiral is sandwiched by two dielectric layers of the same permittivity. The purpose of this paper is to reveal the effects of the top dielectric layer on the radiation characteristics, including the AR, input impedance, and gain for a circularly polarized antenna.

Manuscript received October 26, 2002; revised August 8, 2003.

H. Nakano, K. Hitosugi, and J. Yamauchi are with the College of Engineering, Hosei University, Tokyo, Japan 184-8584 (e-mail: nakano@k.hosei.ac.jp).

M. Ikeda was with the College of Engineering, Hosei University, Tokyo, Japan 184-8584. He is now with Nippon Antenna Company, Ltd., Tokyo, 1168561, Japan.

Digital Object Identifier 10.1109/TAP.2004.829404

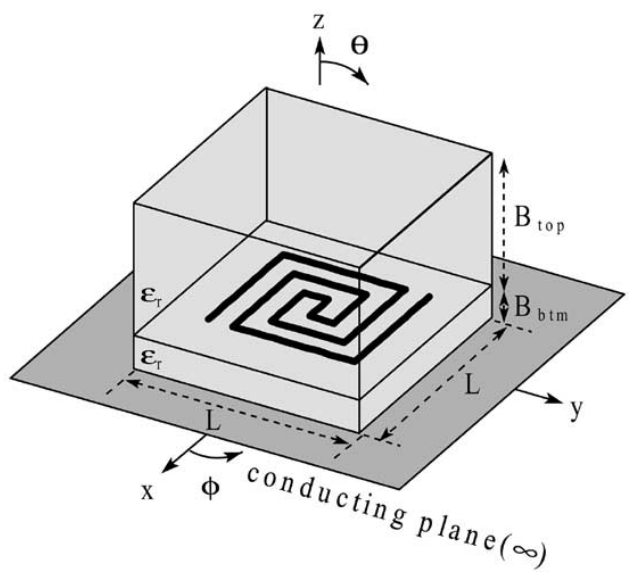

(a)

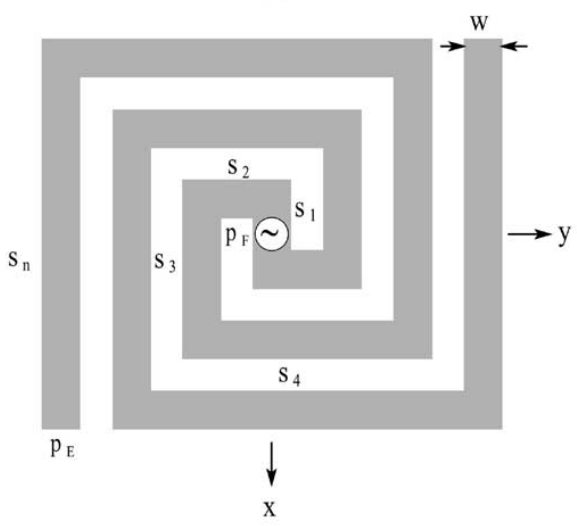

(b)

Fig. 1. Two-arm infinitesimally thin spiral antenna sandwiched by two dielectric layers of the same relative permittivity. (a) Perspective view and (b) spiral arms. The dielectric layers have a square shape with side length $\mathrm{L}$.

Note that the spiral is infinitesimally thin, the top and bottom dielectric layers are of finite extent, and the conducting plane is assumed to be of infinite extent. This corresponds to a small antenna for mobile communications, sitting on the roof of an automobile.

For analysis, the finite-difference time domain (FDTD) method is adopted [7], [8], where Yee's rectangular mesh [9] is used with Liao's second order absorbing boundary condition [10]. It is noted that the spiral arms are symmetric with respect to the feed point, and hence the symmetry condition is applied to reduce the computational space for the FDTD method.

First, techniques of evaluating the antenna characteristics on the basis of the FDTD method are briefly summarized. Second, the numerical results are presented. The periodic variation in the $\mathrm{AR}$ and input impedance as a function of the top dielectric layer thickness $\mathrm{B}_{\text {top }}$ is discussed. The behavior of the gain as a function of $B_{\text {top }}$ is also presented. 
Third, one method of improving the AR is presented. The AR is improved by suppressing the wave reflected from the upper surface of the top dielectric layer. For this, a layer, called the "anti-reflection layer (ARL)," is added to the top dielectric, as shown in Fig. 9. This idea derives from the concept of plane wave propagation in unbounded layers. The effects of the ARL on the input impedance and gain are also presented and discussed.

\section{CONFIGURATION}

Fig. 1(a) shows the configuration and coordinate system of a two-arm spiral antenna, which is infinitesimally thin and sandwiched by two dielectric layers of the same relative permittivity $\varepsilon_{\mathrm{r}}$. The dielectric layers have a square shape with side length L.

The spiral is located at height $\mathrm{B}_{\mathrm{btm}}$ (bottom dielectric layer thickness) above a conducting plane of infinite extent. The two spiral arms of width $\mathrm{w}$ are symmetrically wound with respect to feed point $P_{F}$. Each spiral arm is composed of $n$ filaments. The filament lengths along the centerline of the arm are $s_{1}, s_{2}, s_{3}, \ldots s_{n}$. The distance (thickness) from the spiral plane to the upper surface of the top dielectric is denoted as B top.

To simplify the discussion, the following parameters are fixed: arm width $\mathrm{w}=2 \Delta=0.02 \lambda_{8}$, number of filaments per arm $\mathrm{n}=7$, and filament lengths $\mathrm{s}_{1}=2 \Delta=0.02 \lambda_{8}, \mathrm{~s}_{\mathrm{i}}$ $=2(\mathrm{i}-1) \mathrm{s}_{1}$ for $\mathrm{i}=2,3, \ldots 6$, and $\mathrm{s}_{7}=21 \Delta=0.21 \lambda_{8}$, where $\Delta=0.375 \mathrm{~mm}=0.01 \lambda_{8}(\Delta$ is the FDTD cell size $)$, and $\lambda_{8}$ is the free space wavelength at a test frequency of $8 \mathrm{GHz}$. In this case, the spiral has a circumference [approximately $2(22 \Delta+26 \Delta)]$ of 1.24 guided wavelengths at $8 \mathrm{GHz}$, where the guided wavelength is assumed to be $\lambda_{8} /\left[\left(\varepsilon_{\mathrm{r}}+1\right) / 2\right]^{1 / 2}$ with $\varepsilon_{\mathrm{r}}=2.33$ and $\mathrm{B}_{\text {top }}=0$ (no top dielectric layer). This circumference supports first-mode radiation [1].

The $\varepsilon_{\mathrm{r}}, \mathrm{B}_{\mathrm{btm}}, \mathrm{B}_{\mathrm{top}}$, and $\mathrm{L}$ are varied subject to the objectives of the analysis.

\section{Summary OF NumericAl Method AND VALidation OF COMPUTER PROGRAMS}

The analysis is performed using the FDTD method [7]-[9], together with Liao's second order absorbing boundary condition [10]. Due to structural symmetry with respect to the feed point $\mathrm{P}_{\mathrm{F}}$, the rectangular coordinate components of the electric field $\mathbf{E}$ and magnetic field $\mathbf{H}$ have the following relationships: $\mathrm{E}_{\mathrm{i}}(\mathrm{x}, \mathrm{y}, \mathrm{z})=\mathrm{E}_{\mathrm{i}}(-\mathrm{x},-\mathrm{y}, \mathrm{z})$ and $\mathrm{H}_{\mathrm{i}}(\mathrm{x}, \mathrm{y}, \mathrm{z})=\mathrm{H}_{\mathrm{i}}(-\mathrm{x},-\mathrm{y}, \mathrm{z})$ for $\mathrm{i}=\mathrm{x}$ and $\mathrm{y}$, and $\mathrm{E}_{\mathrm{z}}(\mathrm{x}, \mathrm{y}, \mathrm{z})=-\mathrm{E}_{\mathrm{z}}(-\mathrm{x},-\mathrm{y}, \mathrm{z})$ and $\mathrm{H}_{\mathrm{z}}(\mathrm{x}, \mathrm{y}, \mathrm{z})=-\mathrm{H}_{\mathrm{z}}(-\mathrm{x},-\mathrm{y}, \mathrm{z})$. Use of these relationships allows one to reduce the calculation space to one-half of the original space $\left(\mathrm{N}_{\mathrm{x}} \Delta \mathrm{x} \times \mathrm{N}_{\mathrm{y}} \Delta \mathrm{y} \times \mathrm{N}_{\mathrm{z}} \Delta \mathrm{z}\right.$, with $\mathrm{N}_{\mathrm{i}}(\mathrm{i}=\mathrm{x}, \mathrm{y}, \mathrm{z})$ being integers). The current I on each spiral arm is calculated by integrating the magnetic field $\mathbf{H}$ around the spiral arm (Ampere's circuital law).

The far-field (radiation field) $\mathbf{E}_{\mathrm{f}}$ is evaluated by applying the equivalence theorem [11], where two equivalent current densities on a surface $\mathrm{S}$ enclosing the antenna are used: electric current density $\mathbf{J}_{\mathrm{s}}=-\mathbf{H}_{\mathrm{s}} \times \widehat{\mathrm{n}}$ and magnetic current density $\mathbf{M}_{\mathrm{s}}=\mathbf{E}_{\mathrm{s}} \times \widehat{\mathrm{n}}$, where $\mathbf{H}_{\mathrm{s}}$ and $\mathbf{E}_{\mathrm{s}}$ are, respectively, the mag- netic and electric fields on the enclosing surface $S$, and $\overparen{\mathrm{n}}$ is the normal unit vector pointing out of the enclosing surface $S$.

The spiral is a circularly polarized antenna, and hence it is useful to decompose the radiation field $\mathbf{E}_{\mathrm{f}}(\mathrm{r}, \theta, \phi)$, expressed as $\mathrm{E}_{\theta} \hat{\theta}+\mathrm{E}_{\phi} \hat{\phi}$, into a right-hand circularly polarized (RHCP) wave component $\mathrm{E}_{\mathrm{R}}$ and a left-hand circularly polarized (LHCP) wave component $\mathrm{E}_{\mathrm{L}}: \mathbf{E}_{\mathrm{f}}(\mathrm{r}, \theta, \phi)=\mathrm{E}_{\mathrm{R}}(\hat{\theta}-\mathrm{j} \hat{\phi})+\mathrm{E}_{\mathrm{L}}(\hat{\theta}+\mathrm{j} \hat{\phi})$, where $\hat{\theta}$ and $\hat{\phi}$ are unit vectors in the spherical coordinate system $(\mathrm{r}, \theta, \phi)$. The decomposition leads to the relationships $\mathrm{E}_{\mathrm{R}}=\left(\mathrm{E}_{\theta}+\mathrm{j} \mathrm{E}_{\phi}\right) / 2$ and $\mathrm{E}_{\mathrm{L}}=\left(\mathrm{E}_{\theta}-\mathrm{j} \mathrm{E}_{\phi}\right) / 2$, with $\mathrm{E}_{\mathrm{R}}, \mathrm{E}_{\mathrm{L}}, \mathrm{E}_{\theta}$, and $\mathrm{E}_{\phi}$ all being complex numbers. Note that the relationship $2\left(\left|\mathrm{E}_{\mathrm{R}}\right|^{2}+\left|\mathrm{E}_{\mathrm{L}}\right|^{2}\right)=\left|\mathrm{E}_{\theta}\right|^{2}+\left|\mathrm{E}_{\phi}\right|^{2}$ exists.

Using $\mathrm{E}_{\mathrm{R}}$ and $\mathrm{E}_{\mathrm{L}}$, the $\mathrm{AR}$ is calculated as $\left(\left|\mathrm{E}_{\mathrm{R}}\right|+\right.$ $\left.\left|E_{L}\right|\right) /|| E_{R}|-| E_{L}||$. The gain for a RHCP wave, which the spiral shown in Fig. 1(a) is expected to radiate due to its winding sense, is given as $\mathrm{G}_{\mathrm{R}}=\left|\mathrm{E}_{\mathrm{R}}\right|^{2} \mathrm{r}^{2} /\left(30 \mathrm{P}_{\text {in }}\right)$, where $\mathrm{P}_{\text {in }}=\left(\mathrm{I}_{0 \mathrm{~m}} / \sqrt{2}\right)^{2} \mathrm{R}_{\text {in }}$, with $\mathrm{I}_{0 \mathrm{~m}}$ being the peak value of the current at the input terminals and $R_{\text {in }}$ being the resistive component of the input impedance $Z_{\text {in }}=R_{\text {in }}+j X_{\text {in }}$.

The developed FDTD computer programs are validated by comparing results with those obtained using the method of moments (MoM) [4]. The following parameters are used for the validation; $\left(\varepsilon_{\mathrm{r}}, \mathrm{B}_{\mathrm{top}}, \mathrm{L}\right)=(1,0, \infty)$ and $\left(\varepsilon_{\mathrm{r}}, \mathrm{B}_{\text {top }}, \mathrm{L}\right)=(2.33,0, \infty)$ in Fig. 1, together with $\mathrm{B}_{\mathrm{btm}}=0.13 \lambda_{8}\left(\equiv \mathrm{B}_{\mathrm{btm}}^{0}\right)$ and the configuration parameters defined in Section II. The parameters $\left(\varepsilon_{\mathrm{r}}, \mathrm{B}_{\text {top }}, \mathrm{L}\right)=(1,0, \infty)$ represent a spiral in free-space with a conducting plane of infinite extent. The parameters $\left(\varepsilon_{\mathrm{r}}, \mathrm{B}_{\text {top }}, \mathrm{L}\right)=(2.33,0, \infty)$ represent a spiral printed on a dielectric layer of infinite extent, backed by a conducting plane of infinite extent. The FDTD results for these two spiral antennas (the current distribution I, far-field $\mathbf{E}_{\mathrm{f}}, \mathrm{AR}$, and gain $\mathrm{G}_{\mathrm{R}}$ ) are in good agreement with the MoM results. After validating the developed FDTD computer programs, the antenna characteristics are investigated in Sections IV and V.

\section{ANTENNA CHARACTERISTICS}

Preliminary analysis is performed to investigate the effects of the finite side length $\mathrm{L}$ on the antenna characteristics. For this, three values of the bottom dielectric layer thickness $\mathrm{B}_{\mathrm{btm}}\left(0.1 \lambda_{8} \equiv \mathrm{B}_{\mathrm{btm}}^{-}, 0.13 \lambda_{8} \equiv \mathrm{B}_{\mathrm{btm}}^{0}\right.$, and $\left.0.16 \lambda_{8} \equiv \mathrm{B}_{\mathrm{btm}}^{+}\right)$ are used, with $\varepsilon_{\mathrm{r}}=2.33$ and $\mathrm{B}_{\text {top }}=0$ (no top dielectric layer). The remaining configuration parameters are defined in Section II.

The analysis as a function of the side length $\mathrm{L}$ reveals the following facts: For $\mathrm{L} \geq 0.8 \lambda_{8}$, (1) the input impedances for the three values $\mathrm{B}_{\mathrm{btm}}^{-}, \mathrm{B}_{\mathrm{btm}}^{0}$, and $\mathrm{B}_{\mathrm{btm}}^{+}$converge, (2) the AR for $\mathrm{B}_{\mathrm{btm}}^{0}$ is the lowest (less than $3 \mathrm{~dB}$ ) for the three values of $\mathrm{B}_{\mathrm{btm}}$, and (3) the gain $G_{R}$ for $B_{b t m}^{0}$ is the highest for the three values of $B_{b t m}$. For reference, the radiation patterns for $L \geq 0.8 \lambda_{8}$ are shown in Fig. 2.

Based on the above results, $\mathrm{B}_{\mathrm{btm}}$ and $\mathrm{L}$ are fixed to be $\mathrm{B}_{\mathrm{btm}}^{0}\left(=0.13 \lambda_{8}\right)$ and $0.8 \lambda_{8}$, respectively, for $\varepsilon_{\mathrm{r}}=2.33$. Only the top dielectric layer thickness $B_{\text {top }}$ is varied in the following discussion.

The top dielectric layer of thickness $B_{\text {top }}$ is regarded as a waveguide structure for the wave generated by the spiral. When 


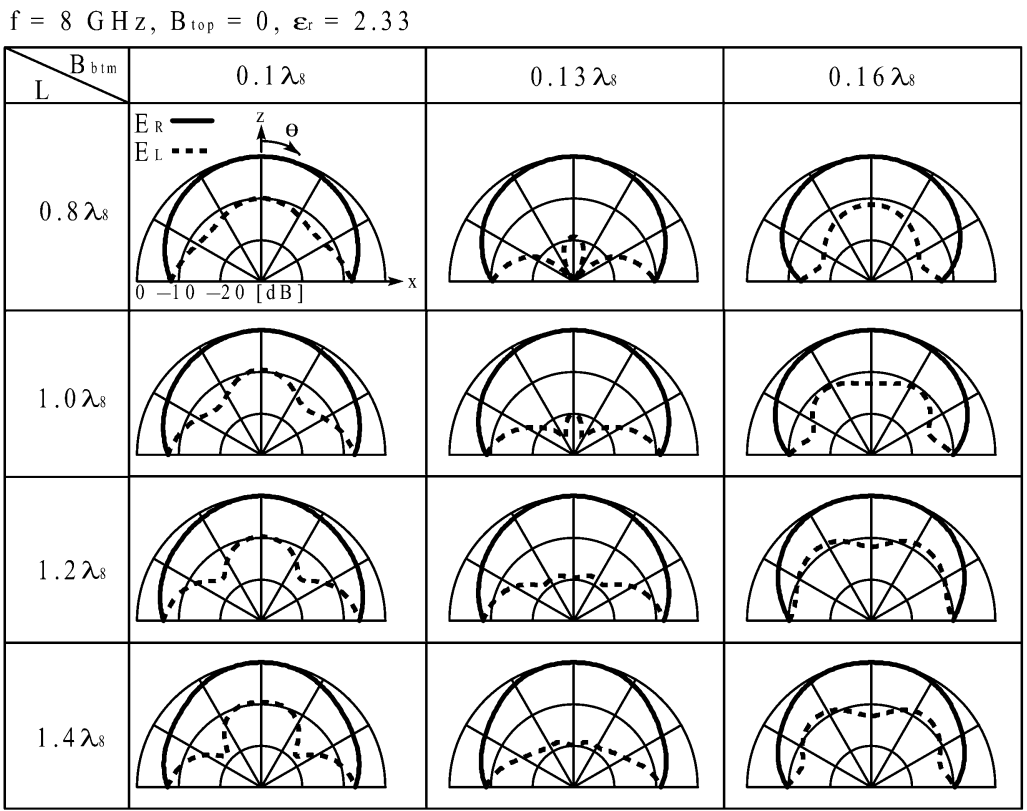

Fig. 2. Radiation patterns for $\mathrm{L} \geq 0.8 \lambda_{8}$ at a test frequency of $8 \mathrm{GHz}$.

the wave reaches the upper surface of the top dielectric at height $\mathrm{z}=\mathrm{B}_{\mathrm{btm}}+\mathrm{B}_{\mathrm{top}}$, it is desired that the wave completely radiates into free-space. If this radiation from the dielectric surface is not complete, part of the wave is reflected back in the $-\mathrm{z}$ direction. The reflected wave illuminates the spiral and disturbs the current distribution along the spiral, changing the antenna characteristics.

It is expected that the illuminations for $\mathrm{B}_{\text {top }}=\mathrm{B}$ and $\mathrm{B}_{\text {top }}=$ $\mathrm{B}+\Delta \mathrm{B}$ will be similar, if the wave for $\mathrm{B}_{\text {top }}=\mathrm{B}+\Delta \mathrm{B}$ experiences a phase change of $2 \mathrm{~m} \pi \mathrm{rad}$, passing through length $2 \Delta \mathrm{B}$, where $\mathrm{m}$ is an integer. Note that the wave for $\mathrm{B}_{\text {top }}=\mathrm{B}+\Delta \mathrm{B}$ passes through a section of length $\Delta \mathrm{B}$ twice, first as an incident wave and then as a reflected wave. The phase change $2 \mathrm{~m} \pi \mathrm{rad}$ corresponds to $\Delta \mathrm{B}=\mathrm{m}\left(\lambda_{\mathrm{g}} / 2\right)$, where $\lambda_{\mathrm{g}}$ is the guided wavelength in the dielectric. This repetitive illumination means that the input impedance and AR (on the $z$ axis) should change with a period of approximately $\lambda_{\mathrm{g}} / 2$ with respect to $\mathrm{B}_{\text {top }}$.

The solid lines in Fig. 3 show the input impedance $\mathrm{Z}_{\text {in }}=$ $\mathrm{R}_{\mathrm{in}}+\mathrm{j} \mathrm{X}_{\mathrm{in}}$ as a function of the thickness $\mathrm{B}_{\text {top }}$ for an antenna depicted in Fig. 1 (the white dots will be explained later in Section $\mathrm{V})$. Note that $\mathrm{B}_{\text {top }}$ is normalized to the guided wavelength $\lambda_{\mathrm{g}}$ in the dielectric, where $\lambda_{\mathrm{g}}=\lambda_{8} / \varepsilon_{\mathrm{r}}^{1 / 2}$ is adopted, assuming that the guided wavelength for the structure of a finite dielectric layer is close to the guided wavelength for a plane wave traveling in an unbounded space filled with a dielectric of relative permittivity $\varepsilon_{\mathrm{r}}$. Detailed investigations show that maxima of the input resistance $\mathrm{R}_{\text {in }}$ appear with a period slightly larger than $0.5 \lambda_{\mathrm{g}}$ with respect to $\mathrm{B}_{\mathrm{top}}$. This approximate period holds true for maxima of the input reactance $\mathrm{X}_{\mathrm{in}}$ as well.

The radiation patterns are shown in Fig. 4 as a function of the thickness $B_{\text {top. }}$. It is found that, as the thickness $B_{\text {top }}$ increases, the radiation beam becomes narrower and side-lobe levels become higher.

The effect of thickness $B_{\text {top }}$ on the AR is noticeable, as shown in the solid lines in Fig. 5, where the AR is the value on the $z$ axis (the white dots will be explained later in Section V). The

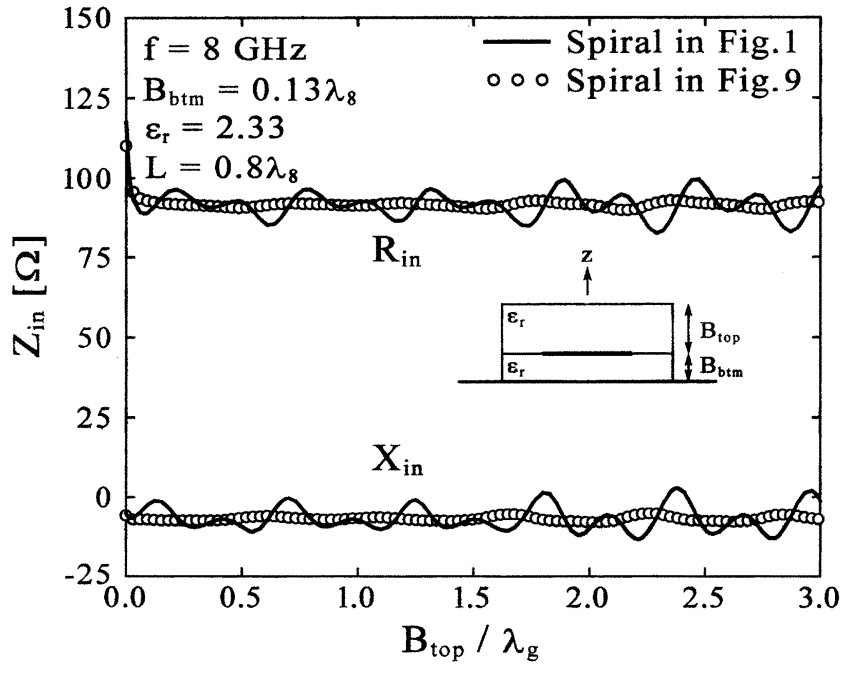

Fig. 3. Input impedance $Z_{\text {in }}=R_{\text {in }}+j X_{\text {in }}$ as a function of the top dielectric layer thickness $B_{\text {top }}$ at a test frequency of $8 \mathrm{GHz}$. The solid lines show $Z_{\text {in }}$ for an antenna depicted in Fig. 1. The white dots show $Z_{\text {in }}$ for an antenna depicted in Fig.9.

AR has a period slightly larger than $0.5 \lambda_{\mathrm{g}}$ with respect to $\mathrm{B}_{\text {top }}$. The degradation in the AR is due to currents reflected from the arm ends, which radiate an undesired LHCP wave, opposing the RHCP wave.

The combination of a current flowing toward the arm end $\mathrm{P}_{\mathrm{E}}$ and a reflected current from the arm end $\mathrm{P}_{\mathrm{E}}$ appears in the form of a standing wave current in a region near the arm end. Fig. 6 shows the current distribution as a function of the thickness $B_{\text {top }}$, where the vertical axis on the left side is for the real $\left(\mathrm{I}_{\mathrm{r}}\right.$ : solid line) and imaginary $\left(\mathrm{I}_{\mathrm{i}}\right.$ : broken line) parts of the current $\left(\mathrm{I}=\mathrm{I}_{\mathrm{r}}+\mathrm{j} \mathrm{I}_{\mathrm{i}}\right)$, as well as the amplitude $(|\mathrm{I}|$ : dotted line $)$. The vertical axis on the right side is for the phase of the current. Note that since the currents on the two arms are symmetric with respect to the feed point $\mathrm{P}_{\mathrm{F}}$, only the current distribution on one arm is presented. 


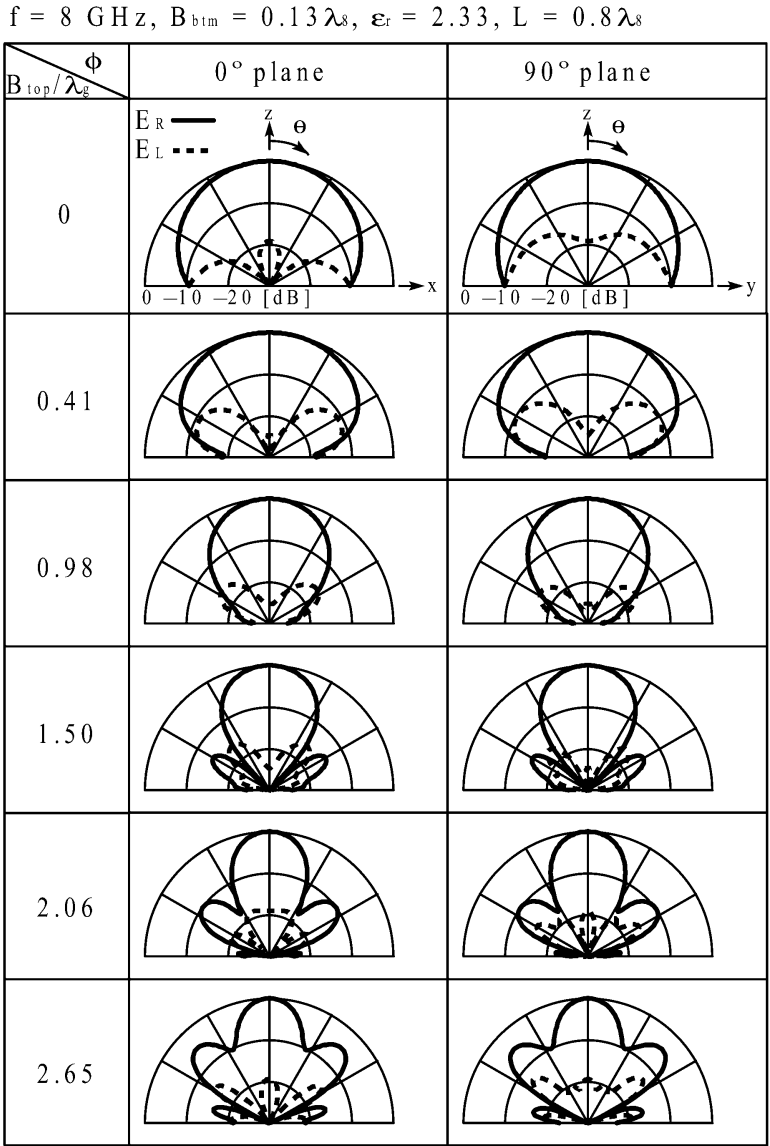

Fig. 4. Radiation patterns as a function of the top dielectric layer thickness $\mathrm{B}_{\text {top }}$ at a test frequency of $8 \mathrm{GHz}$.

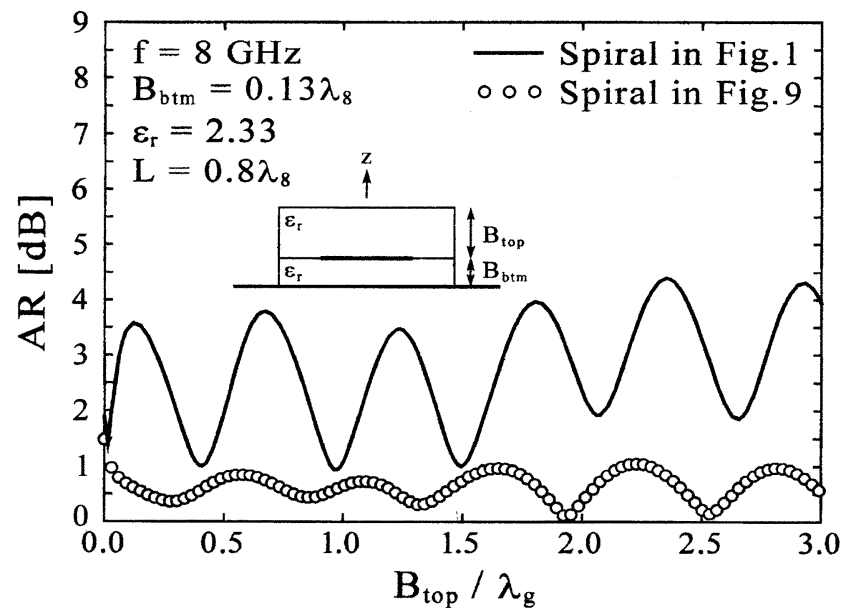

Fig. 5. AR as a function of the top dielectric layer thickness $B_{\text {top }}$ at a test frequency of $8 \mathrm{GHz}$. The solid lines show AR for an antenna depicted in Fig. 1. The white dots show AR for an antenna depicted in Fig. 9.

As seen from the amplitude distributions in the region near the arm end $\mathrm{P}_{\mathrm{E}}$, the standing waves in Fig. 6(b), (d), and (f) are higher than those in Fig. 6(a), (c), and (e). In other words, the reflected currents in Fig. 6(b), (d), and (f) are larger than those in Fig. 6(a), (c), and (e). It follows that the axial ratios of the radiation fields from the currents of Fig. 6(b), (d), and (f) are degraded, compared with those of Fig. 6(a), (c), and (e), as shown in Fig. 5.
The solid line in Fig. 7 shows the gain $\mathrm{G}_{\mathrm{R}}$ for a RHCP wave in the $z$ direction as a function of thickness $\mathrm{B}_{\text {top }}$ (the white dots will be explained later in Section V). As $B_{\text {top }}$ increases, the gain increases. However, after the gain reaches a maximum value, it decreases due to rising side-lobe levels.

Note that the maximum gain (approximately $13 \mathrm{dBi}$ in Fig. 7, obtained for an infinite ground plane) is not significantly affected by the size of the ground plane. When the ground plane has a square shape, the maximum gain is approximately $13 \mathrm{dBi}$, provided that the side length of the ground plane is greater than $0.8 \lambda_{8}$. Also, note that the gain shown in Fig. 7 is confirmed by numerical experiments using electromagnetic wave solvers: HFSS (finite element method, Ansoft Corporation) and MW-Studio (finite integration method, CST Corporation).

The gain is not determined only by the physical area of the top dielectric surface $(\mathrm{L} \times \mathrm{L})$. The gain is also related to the length of the top dielectric $\left(\mathrm{B}_{\text {top }}\right)$, as in the case of a dielectric rod antenna, which usually has a long antenna length relative to the wavelength $\lambda$ and a small open end surface area, defined as $A_{p}$ [12]. (Note that the gain of the dielectric rod antenna is expressed as $4 \pi \mathrm{A}_{\text {eff }} / \lambda^{2}$, where $\mathrm{A}_{\text {eff }}$ is the effective area and is wider than the physical surface area $A_{p}$.) The length of the top dielectric affects the electric field distribution over a planar surface at $\mathrm{z}=\mathrm{z}_{\mathrm{ob}}$ (parallel to the $x-y$ plane and near the top dielectric surface. See the bottom of Fig. 8). The planar surface at $\mathrm{z}=\mathrm{z}_{\mathrm{ob}}$ is regarded as the secondary source plane for the radiation field. As the in-phase electric field area in the secondary source plane increases, the radiation beam becomes sharper and the gain increases.

Fig. 8 shows the phase distribution of the RHCP wave component $E_{R}$ at $\left(x, y=0, z=z_{o b}\right)$, where the secondary source plane is chosen to be always higher than the top dielectric surface $\left(\mathrm{z}=\mathrm{B}_{\mathrm{btm}}+\mathrm{B}_{\mathrm{top}}\right)$ by $29 \Delta / 2(=5.44 \mathrm{~mm})$. It is found that the in-phase electric field area becomes wider in the sequence $\mathrm{B}_{\text {top }}=0.46 \lambda_{\mathrm{g}}, \mathrm{B}_{\text {top }}=0.80 \lambda_{\mathrm{g}}$, and $\mathrm{B}_{\text {top }}=1.32 \lambda_{\mathrm{g}}$. This is consistent with the gain becoming larger in the same sequence, as shown in Fig. 7.

\section{ANTI-REFLECTION LAYER}

As shown by the solid lines in Figs. 3 and 5, the input impedance and the AR vary as the thickness $B_{\text {top }}$ is changed. These variations are due to a reflected wave from the upper surface of the top dielectric layer at $\mathrm{z}=\mathrm{B}_{\mathrm{btm}}+\mathrm{B}_{\text {top }}$ toward the spiral. This section describes the reduction of the variations in the input impedance and AR. For this, a dielectric layer of thickness $B_{\text {anti }}$ and relative permittivity $\varepsilon_{\mathrm{r}, \text { anti }}$ is added to the upper surface of the top dielectric layer, as shown in Fig. 9.

It is inferred from the concept of plane wave propagation in unbounded layers that the reflected wave is reduced if the thickness $B_{\text {anti }}$ is close to $\lambda_{\mathrm{g} \text {,anti }} / 4$, where $\lambda_{\mathrm{g}, \text { anti }}=\lambda_{8} /\left(\varepsilon_{\mathrm{r}, \text { anti }}\right)^{1 / 2}$ at a test frequency of $8 \mathrm{GHz}$, with $\varepsilon_{\mathrm{r} \text {,anti }}=\left(\varepsilon_{\mathrm{r} 0} \times \varepsilon_{\mathrm{r}}\right)^{1 / 2}$. Note that $\varepsilon_{\mathrm{r} 0}=1$ (free space). This dielectric layer is designated as the ARL.

The effects of the ARL are confirmed by the white dots in Figs. 3 and 5, where a dielectric layer of thickness $B_{\text {anti }}=$ $\lambda_{\mathrm{g}, \text { anti }} / 4=0.2 \lambda_{8}$ and relative permittivity $\varepsilon_{\mathrm{r} \text {,anti }}=1.53$ is used. It is clear that the variations in the input impedance 


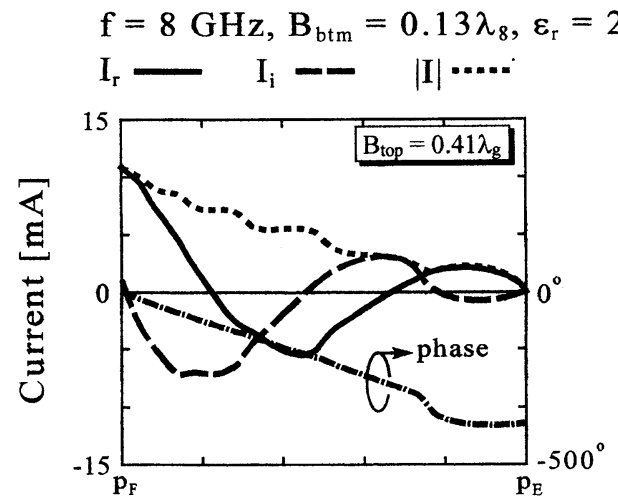

(a)

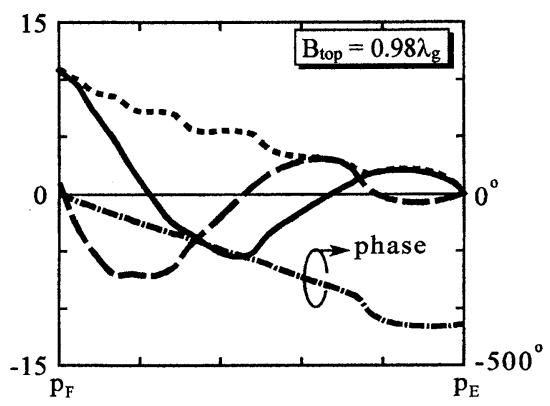

(c)

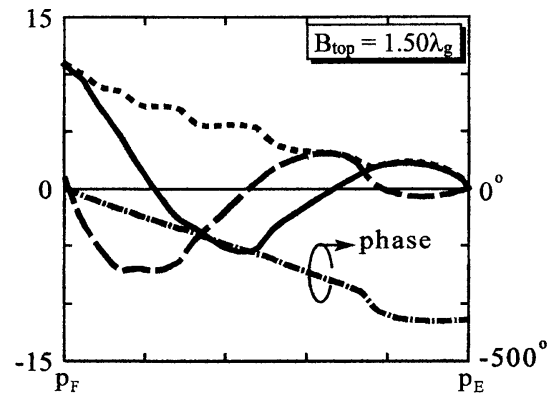

(e)

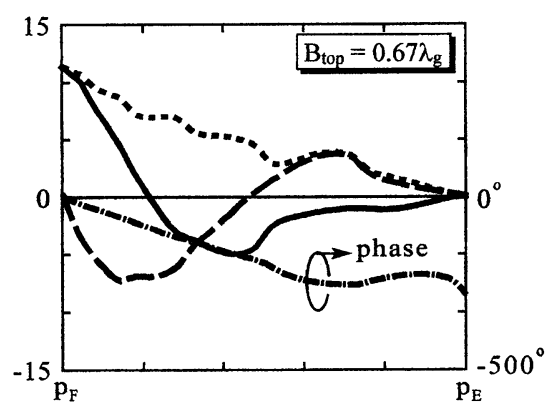

(b)

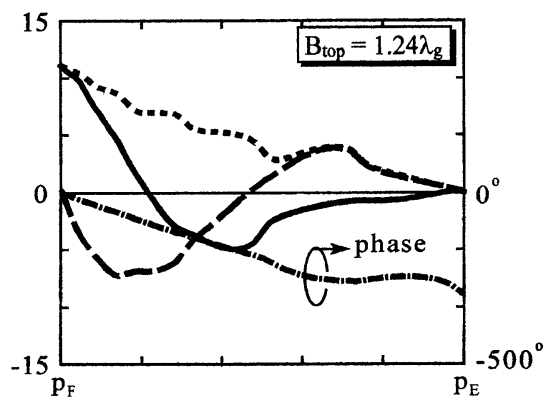

(d)

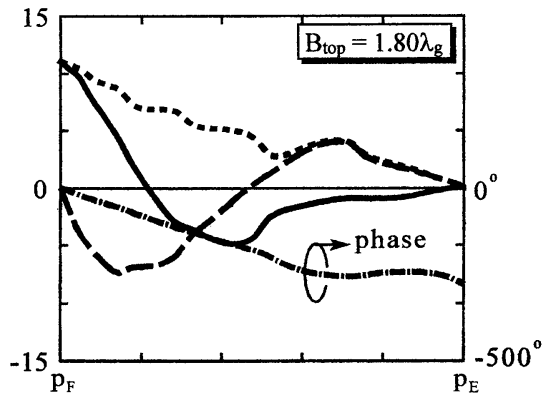

(f)

Fig. 6. Current distribution as a function of the top dielectric layer thickness $\mathrm{B}_{\mathrm{top}}$ at a test frequency of $8 \mathrm{GHz}$.

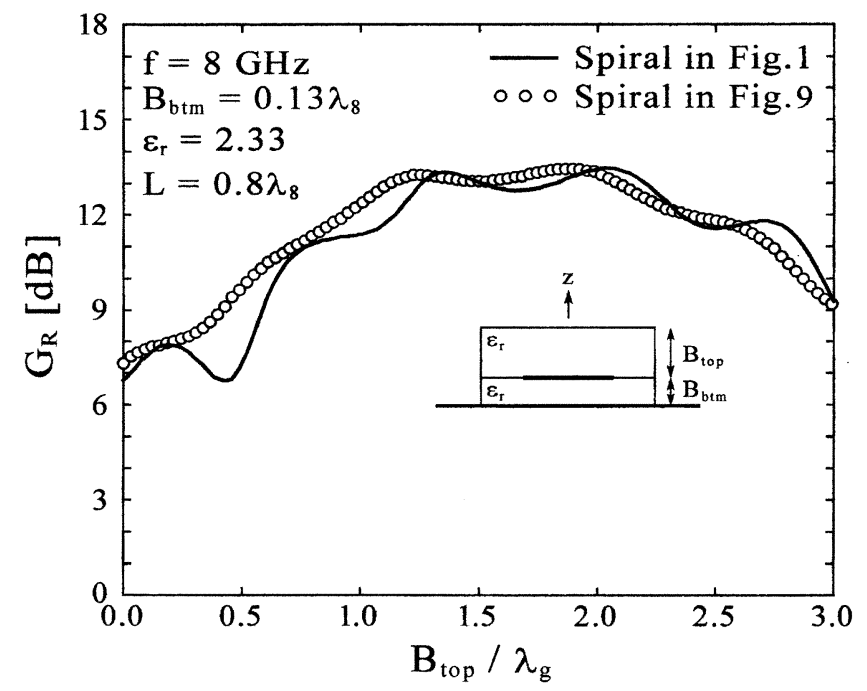

Fig. 7. Gain $\mathrm{G}_{\mathrm{R}}$ for a RHCP wave in the $z$ direction as a function of the top dielectric layer thickness $B_{\text {top }}$ at a test frequency of $8 \mathrm{GHz}$. The solid line shows $\mathrm{G}_{\mathrm{R}}$ for an antenna depicted in Fig. 1. The white dots show $\mathrm{G}_{\mathrm{R}}$ for an antenna depicted in Fig. 9. and the AR are reduced, compared to those for the case without the ARL (the solid lines in Figs. 3 and 5). It can also be seen from the white dots in Fig. 7 that the gain for the spiral with the ARL is smoother than that for the spiral without the ARL. (Note that the gain of a microstrip patch antenna with a top dielectric layer and an ARL shows behavior similar to that shown in Fig. 7).

So far, a test frequency of $8 \mathrm{GHz}$ has been used for the above discussion. Next, the frequency responses of the antenna characteristics are investigated, focusing on parameters $\mathrm{B}_{\text {top }}=1.92 \lambda_{\mathrm{g}}, \mathrm{B}_{\text {anti }}=\lambda_{\mathrm{g}, \text { anti }} / 4=0.2 \lambda_{8}$, and $\varepsilon_{\mathrm{r} \text {,anti }}=1.53$, which produce an $\mathrm{AR}$ of $0.3 \mathrm{~dB}$, as seen from the white dots in Fig. 5.

Fig. 10 shows the AR and gain as a function of frequency. It is found that the frequency bandwidth for a 3-dB AR criterion is approximately $11 \%$. Within this bandwidth, the gain $\mathrm{G}_{\mathrm{R}}$ is approximately $13 \mathrm{dBi}$, which is $6 \mathrm{dBi}$ higher than that for a printed spiral without the top dielectric and ARL $\left(B_{\text {top }}=0\right.$ and $B_{\text {anti }}=0$ ). Note that the voltage standing wave ratio is less than 1.2 within the same $11 \%$ bandwidth. 


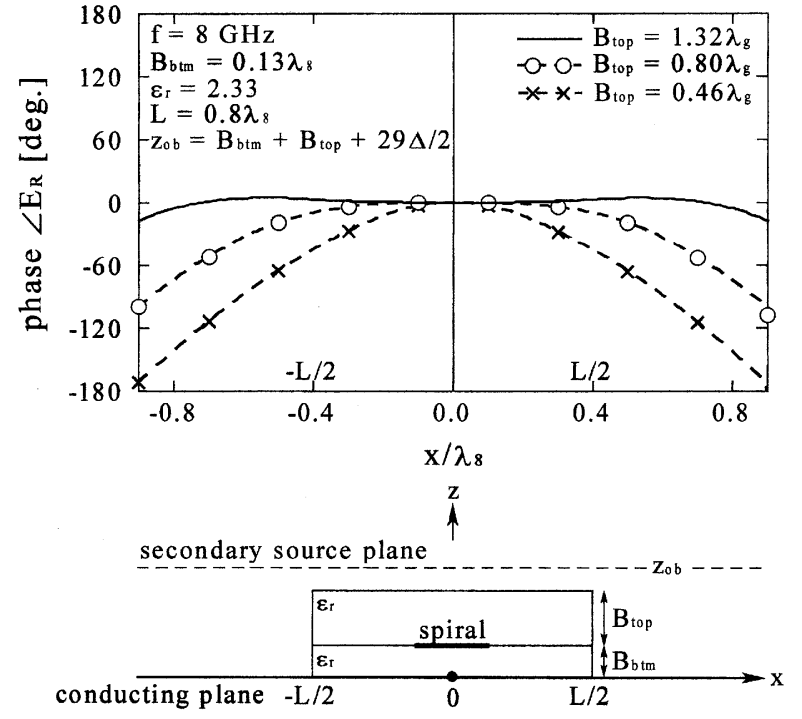

Fig. 8. Phase distribution of the RHCP wave component at ( $\mathrm{x}, \mathrm{y}=0, \mathrm{z}=$ $\mathrm{z}_{\mathrm{ob}}=\mathrm{B}_{\mathrm{btm}}+\mathrm{B}_{\mathrm{top}}+29 \Delta / 2$ ).

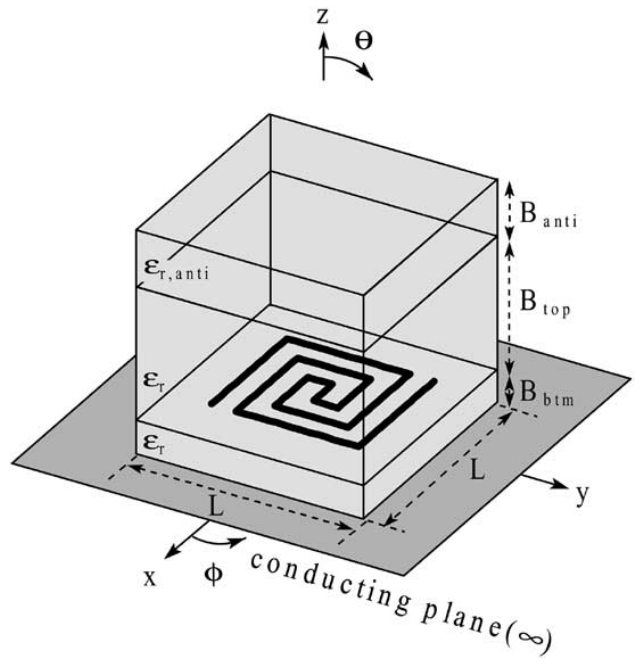

Fig. 9. ARL which has thickness $B_{\text {anti }}$ and relative permittivity $\varepsilon_{\mathbf{r} \text {,anti }}$.

\section{CONCLUSION}

This paper presents a new spiral antenna, where the spiral is sandwiched by bottom and top finite-size dielectric layers of the same relative permittivity $\varepsilon_{\mathrm{r}}$ and backed by a conducting plane of infinite extent. The antenna characteristics as a function of the thickness of the top dielectric layer $\mathrm{B}_{\text {top }}$ are calculated using the FDTD method. As $B_{\text {top }}$ increases, the input impedance and AR show oscillatory variations, with a period slightly larger than one-half of the guided wavelength of a plane wave propagating in an unbounded dielectric material. It is also found that, as $\mathrm{B}_{\text {top }}$ increases, the radiation pattern becomes narrower and the gain reaches a maximum value. However, as $B_{\text {top }}$ further increases, the gain decreases due to rising side-lobe levels.

To reduce the oscillatory variations in the input impedance and $A R$ with respect to $B_{\text {top }}$, a layer, called the ARL, is added to the top dielectric layer. The ARL has a thickness of one-quarter guided wavelength $\left(\lambda_{\mathrm{g}, \text { anti }} / 4\right)$, with a relative permittivity of $\varepsilon_{\mathrm{r}, \text { anti }}=\left(\varepsilon_{\mathrm{r} 0} \times \varepsilon_{\mathrm{r}}\right)^{1 / 2}$, where $\varepsilon_{\mathrm{r} 0}=1$. It is confirmed that

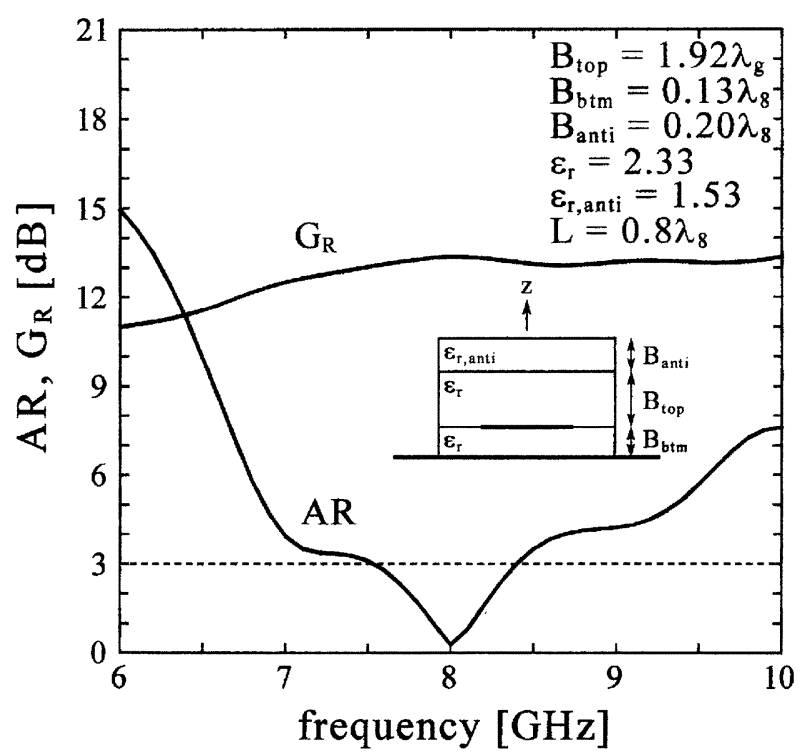

Fig. 10. Frequency responses of $A R$ and gain $\left(G_{R}\right)$ for an antenna having an ARL.

the variation of both the AR and input impedance is reduced. The frequency response of a representative spiral antenna with an ARL shows that the AR bandwidth is approximately $11 \%$. Within this bandwidth, the gain $\mathrm{G}_{\mathrm{R}}$ for a RHCP wave is approximately $13 \mathrm{dBi}$. This gain value is $6 \mathrm{dBi}$ higher than that for a printed spiral without the top dielectric and ARL.

\section{ACKNOWLEDGMENT}

The authors thank H. Yasui, Y. Okabe, H. Mimaki, and V. Shkawrytko for their kind discussions and assistance in the preparation of this manuscript.

\section{REFERENCES}

[1] J. A. Kaiser, "The Archimedean two-wire spiral antenna," IRE Trans. Antennas Propagat., vol. AP-8, pp. 312-323, May 1960.

[2] H. Nakano, K. Nogami, S. Arai, H. Mimaki, and J. Yamauchi, "A spiral antenna backed by a conducting plane reflector," IEEE Trans. Antennas Propagat., vol. AP-34, pp. 791-796, June 1986.

[3] J. J. H. Wang and V. K. Tripp, "Design of multioctave spiral-mode microstrip antennas," IEEE Trans. Antennas Propagat., vol. 39, pp. 332-335, Mar. 1991.

[4] H. Nakano, S. R. Kerner, and N. G. Alexopoulos, "The moment method solution for printed wire antennas of arbitrary configuration," IEEE Trans. Antennas Propagat., vol. 36, pp. 1667-1674, Dec. 1988.

[5] N. J. Champagne II, J. T. Williams, and D. R. Wilton, "Analysis of resistively loaded, printed spiral antennas," Electromagn., vol. 14, no. 3-4, pp. 363-395, July-Dec. 1994.

[6] H. Nakano, H. Yasui, and J. Yamauchi, "Numerical analysis of two-arm spiral antennas printed on a finite-size dielectric substrate," IEEE Trans. Antennas Propagat., vol. 50, pp. 362-370, Mar. 2002.

[7] A. Taflove, Computational Electrodynamics. Norwood, MA: Artech House, 1995.

[8] T. Uno, Field and Antenna Analysis by FDTD Method: Institute of Electronics, Information and Communications Engineers in Japan, Mar. 1996. Tutorial Text.

[9] K. S. Yee, "Numerical solution of initial boundary value problems involving Maxwell's equations in isotropic media," IEEE Trans. Antennas Propagat., vol. AP-14, pp. 302-307, May 1966.

[10] Z. P. Liao, H. L. Wong, B. P. Yang, and Y. F. Yuan, "A transmitting boundary for transient wave analysis," Science Sinica, ser. A, vol. 27, no. 10, pp. 1063-1076, 1984.

[11] R. F. Harrington, Time-Harmonic Electromagnetic Fields. New York: McGraw-Hill, 1961, pp. 106-110. 
[12] T. Ando, J. Yamauchi, and H. Nakano, "Rectangular dielectric-rod fed by metallic waveguide," in Proc. Inst. Elect. Eng. Microwave Antennas Propagation, vol. 149, Apr. 2002, pp. 92-97.

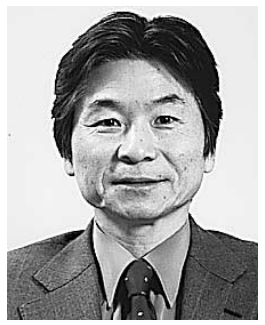

Hisamatsu Nakano (M'75-SM'87-F'92) received the B.E., M.E., and Dr.E. degrees in electrical engineering from Hosei University, Tokyo, Japan, in 1968, 1970, and 1974, respectively.

Since 1973 , he has been a member of the faculty of Hosei University, where he is now a Professor in the Electronic Informatics Department. He has published more than 190 refereed journal papers and 160 international symposium papers on antenna and relevant problems.

Dr. Nakano received the Best Paper Award from the IEE 5th International Conference on Antennas and Propagation in 1987 and the IEEE AP-S Best Application Paper Award (H.A. Wheeler Award) in 1994.

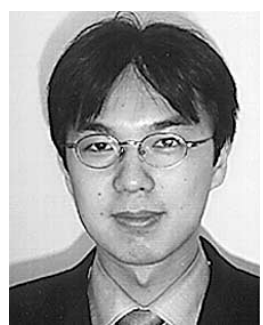

Masakazu Ikeda received the B.E. and M.E. degrees in electronic informatics from Hosei University, Tokyo, Japan, in 2001 and 2003, respectively.

He joined Nippon Antenna Company, Ltd., Tokyo, Japan, in 2003.

Mr. Ikeda is a Member of the Institute of Electronics, Information and Communication Engineers (IEICE) of Japan.

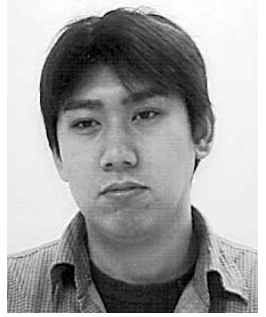

Kazuo Hitosugi received the B.E. degree in elecronic informatics from Hosei University, Tokyo, Japan, in 2003, where he is currently working toward the M.E. degree.

Mr. Hitosugi is a member of the Institute of Electronics, Information and Communication Engineers (IEICE) of Japan.

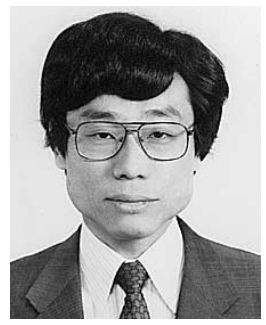

Junji Yamauchi (M'85) was born in Nagoya, Japan, on August 23, 1953. He received the B.E., M.E., and Dr.E. degrees from Hosei University, Tokyo, Japan, in 1976, 1978, and 1982, respectively.

From 1984 to 1988 , he served as a Lecture in the Electrical Engineering Department, Tokyo Metropolitan Technical College. Since 1988, he has been a member of the faculty of Hosei University, where he is now a Professor of electronic informatics. His research interests include optical waveguides and circularly polarized antennas.

Dr. Yamauchi is a Member of the Optical Society of America (OSA) and the Institute of Electronics, Information and Communication Engineers (IEICE) of Japan. 